\section{RANCANG BANGUN PABRIK PELLET \\ DARI PLASTIK REKLAIM}

\section{Oleh : Agustin Suraswati dan Pramono}

\section{ABSTRACT}

The purpose of this design is to find out process of production and the relation betwen cost, sell price and percentage of break event point. Production of capacity planned is $975 \mathrm{~kg}$ per day,so that in one a year with 288 work day the capacity produced is $280.800 \mathrm{~kg}$ of pellet. The economical calculation are as follows = the total capital is fixed capital + working capital $=R p .272 .543 .806,00$, the total production cost is variable cost a year + fixed cost a year $=R p .306 .122 .244,00$, the manufacturing cost $=R p .1 .090,18 / \mathrm{kg}$, the profit calculation before taxing is Rp. 58.917.756,00, after taxing is Rp. 31.902.205,00, the pay out period calculation consist of the percentage of profit to return the capital ( rate of return ) before tuxing is $21,62 \%$, after taxing is $11,71 \%$, and the pay out period before taxing 3 year 1 mounth, after taxing is 5 year 6 mounth; the break even calculation consist of hte break even point is Rp. 242.190.990,00, the percentage of break event point is $66,35 \%$ and the capacity of break event point is 186 ton pellet.

\section{INTISARI}

Rancang bangun ini bertujuan untuk mengetahui proses produksi dan hubungan antara hiaya, harga jual dan prosentase batas rugi laba. Kapaistas produksi yang direncanakan sebesar $975 \mathrm{~kg}$ pellet per hari, sehigga dalam I tahun dengan 288 hari kerja, kapasitas vang dihasilkan $280.800 \mathrm{~kg}$ pellet plastik reklaim. Dalam perhitungan analisa ekonomi diperoleh hasil sebagai berikut $=$ total modal yang terdiri dari tetap dan modal kerja $=R p$. $272,543,806,00$, biaya produksi yang terdiri dari biaya tidak tetap I tahun dan biaya tetap iahun $=$ Rp. 306.122.244.00, Harga pokok produksi $=R p .1 .090,18 / \mathrm{kg}$. Keuntungan $=$ sebelum pajak $R p .58 .917 .756,00$ dan sesudah pajak $=R p .31 .902 .205,00$, keuntungan pengembalian modal sebelum pajak $21.62 \%$ dan sesudah pajak $11.71 \%$, serta waktu pengembalian modal sebelum pajak 3 tahun 7 bulan dan sesudah pajak 5 tahun 6 bulan. Perhitungan nilai batas rugi laba $=66,35 \%$ dan kapasitas hatas rugi laba $=186$ ton pellet .

\section{PENDAHULUAN}

Pada saat-saat terakhir ini limbah plastik semakin menumpuk, apabila hal in dibiarkan terus akan berdampak negatif terhadap lingkungan hidup. Mengingat sifat plastik yang sulit membusuk, maka untuk menanggulangi limbah plastik tersebut dilakukan suatu daur ulang yaitu dengan cara dibuat kembali menjadi pellet, sehingga dapat diolah menjadi produk lain

I nntuk mengolah kembali limbah plastik dari jenis thermoplastik menjadi pel let diperlukan mesin pelletizing (ekstruder dan take up unitnya) dan mesin pencacah limbah plastik.

Pada umumnya pahrik pellet plastik dari reklaim thermoplastik menggunakan teknologi yang tidak begitu sulit, sehingga dapat dilakukan oleh industri perplastikan skala menengah ke bawah.

Mengingat hal tersebut diatas rancang bangun ini dilakukan untuk dapat digunakan sebagai pedoman pada industri perplastikan skala menengah ke bawah, sehingga produk yang dihasilkan secara ekonomis bisa menguntungkan.

\section{MATERI DAN METODE}

Maleri

Materi yang digunakan adalah data yang diperoleh dari survai ke perusahaan plastik, perusahaan pembuat mesin perplastikan dan studi pustaka, serta rancang bangun dan perekayasaan mesin pelletizing dan mesin pencacah limbah plastik

Metoda

Metoda yang digunakan untuk mengolah data yang diperoleh ialah metoda Peter dan Thimmerhaus (1981), dengan cara menghitung

1. Prosentase nilai batas rugi laba.

2. Prosentase pengembalian modal

3. Waktu minimal untuk mengembalikan modal.

\section{HASIL DAN PEMBAHASAN}

A. Kegunaan dan Pemasaran

Kegunaan : sebagai bahan baku reklaim untuk membuat barang-barang plastik reklaim atau untuk campuran pembuatan barang-barang plastik lain. Pemasaran : kebutuhan dalam negeri.

B Diagram Alir Kualitatif

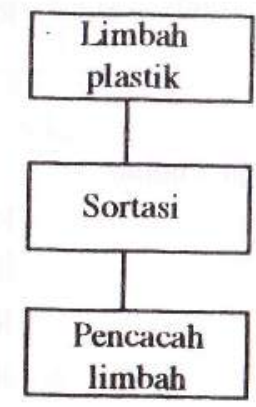

Majalah Barang Kulit, Karet dan Plastik 


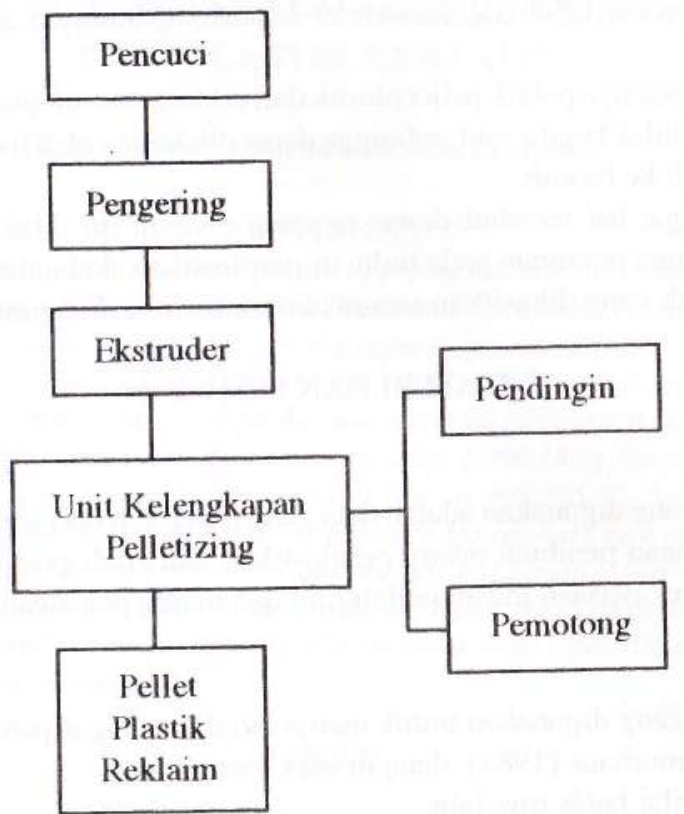

Perhitungan Ekonomi

Hasil perhitungan ekonomi ini akan memberikan gambar tentang besarnya modal yang dibutuhkan untuk mendirikan pabrik pellet reklaim dan untuk menentukanharga pokok produksi, maka harus dihitung dahulu modal tetap dan total biaya produksinya.

1. Perhitungan modal

1.1. Modal Tetap
a. Harga peralatan
b. Pemasangan alat $10 \%$ (a)
c. Instalasi listrik + air $10 \%$ (a)
d. Tanah dan bangunan

Rp. $\quad 56.440 .000$

\begin{tabular}{lr} 
Rp. & 5.644 .000$, \\
Rp. & 5.644 .000$, \\
Rp. & 152.500 .000$, \\
\hline Rp. & 220.228 .000$,
\end{tabular}

\subsection{Modal Kerja}

Dihitung untuk modal kerja 3 bulan.

$\begin{array}{llr}\text { a. Bahan baku } & \mathrm{Rp} & 37800.000, \\ \text { b. pengemasan } & \mathrm{Rp} & 561.600, \\ \text { c. Listrik } & \mathrm{Rp} & 7026.606, \\ \text { d Air } & \mathrm{Rp} & 2097600,\end{array}$

Vol. XIV No. 26 Th. 19981999 e. Gaji Pegawai

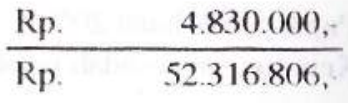

Total modal $=$ modal tetap + modal kerja

$=$ Rp. $220.228 .000,-+$ Rp. 52.315 .806 ,

$=$ Rp. 272.543.806.

2. Perhitungan total biaya produksi.

2.1. Biaya tidak tetap 1 tahun.
a. Bahan Baku
b. Pengemasan
c. I istrik
d. Air

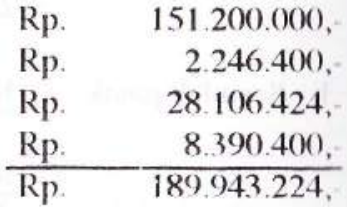

2.2 Biaya tetap 1 tahun
a. Gaj
Rp. $\quad 19.320 .000$
b. Pemeliharaan, $3 \%$ (modal tetap)
$\mathrm{Rp}$
6.606 .840
c. Bunga modal
$15 \%$ modal telap
$18 \%$ modal kerja
d. Penyusutan, $8 \%$ (modal tetap)
c. Biaya umum, $10 \%$ (gaji I tahun)

\begin{tabular}{lr} 
Rp. & 33.034 .200$, \\
Rp. & 37.667 .740$, \\
Rp. & 17.618 .240$, \\
Rp. & 1.932 .000 \\
\hline Rp. & 116.179 .020
\end{tabular}

Total biaya produksi - biaya tidak tetap + biaya tetap

$=$ Rp. 189943.224.- + Rp. 116.179.020

Rp. 306.122 .244

3 Perhitungan harga pokok.

Ilarga pokok = total biaya produksi 1 tahun

jumlah produksi per tahun

$=\frac{\text { Rp. } 306.122 .244,}{280.800}$

Rp. $10 \% 0,18 / \mathrm{kg}$

4. Perhitungan keuntungan

a. Ilasil penjualan I tahun

$280.800 \times \mathrm{Rp} .1 .300$,

b Total biaya produksi

c Keuntungan schelum pajak

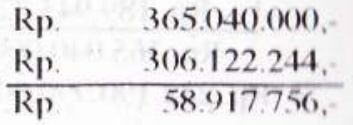

Majalah Barang Kulit, Karet dan 
d. Pajak perusahaan $20 \%$

e. Keuntungan sesudah pajak

\begin{tabular}{ll} 
Rp. & $27.015 .551,-$ \\
\hline Rp. & $31.902 .205,-$
\end{tabular}

5 l'erhitungan pengembalian modal

5.1. Prosen keuntungan untuk mengembalikan modal

Sebelum pajak $=$ Keuntungan sebelum pajak $\times 100 \%$

$$
\begin{aligned}
& =\frac{\text { Total modal }}{=} \frac{\text { Rp. } 58.917 .756,00 \times 100 \%}{\text { Rp. } 272.543 .806,00} \\
& =21,62 \%
\end{aligned}
$$

b. Sesudah pajak = Keuntungan sesudah pajak $\times 100 \%$

$$
\begin{aligned}
& =\frac{\text { Total modal }}{\text { Rp. } 31.902 \cdot 205,00} \times 100 \% \\
& =11,71 \%
\end{aligned}
$$

5.2. Waktu pengembalian modal

$$
\begin{aligned}
& \text { a. Sebelum pajak : } \\
& =\frac{\text { Total modal }}{\text { Keuntungan sebelum pajak + penyusutan }} \times 1 \text { tahun } \\
& =\frac{\text { Rp. } 272.543 .806,00}{\text { Rp. } 58.917 .756,00+\text { Rp. } 17.618 .240,00} \\
& =3 \text { tahun } 7 \text { bulan. } \\
& \text { b. Sesudah pajak: tahun } \\
& =\frac{\text { Total modal }}{\text { Keuntungan sesudah pajak + penyusutan }} \times 1 \text { tahun } \\
& =\frac{\text { Rp. } 272.543 .806,(0)}{\text { Rp } 31.9(12.205,(00+\text { Rp. } 17.618 .240,(0)} \\
& =5 \text { tahun } 6 \text { bulan. }
\end{aligned}
$$

6. Perhitungan batas rugi laba.

6.1. Nilai hatas rugi laba

$$
\begin{aligned}
& =\text { Biaya tetap } \\
& \text { 1- Biaya tidak (etalp } \\
& \text { penjualan } \\
& =\quad \text { Rp. 116.179.020,00 } \\
& \text { 1. Rp. } 189.943 .224,00 \\
& \text { Rp. 365.(40).000,(0) } \\
& =\text { Rp. } 242.19(0.9(),(\%)
\end{aligned}
$$

Iol. XIV No. 26 Th. 1908/1949)
6.2 Prosentase hatas rug laba.

$=\frac{\text { Nilai batas rugi laba }}{\text { Penjolan }} 100 \%$

$$
\text { Penjulan }
$$

$=\frac{\text { Rp. } 242 \cdot 190.990,(0)}{2} \times 100 \%$

Rp. 365.040.000,(0)

$=66,35 \%$

6.3. Kapasitas batas rugi laba.

$=66,35 \% \times 280.800 \mathrm{~kg}$

$=186.310,80 \mathrm{~kg}$

$=186 \mathrm{ton}$.

Kurva batas rugi laba ,

\section{Biaya tidak tetap}

Biaya tetap

Total biaya produksi

Total penjualan

Prosentase hatas rugi laba

$=\mathrm{Rp} \cdot 189943.224,00$

$=R_{p} .116 .179 .020,00$

$=\mathrm{Rp} \cdot 306.122 \cdot 244,00$

$=$ Rp. 36.5040.000,00

$=66.35 \%$

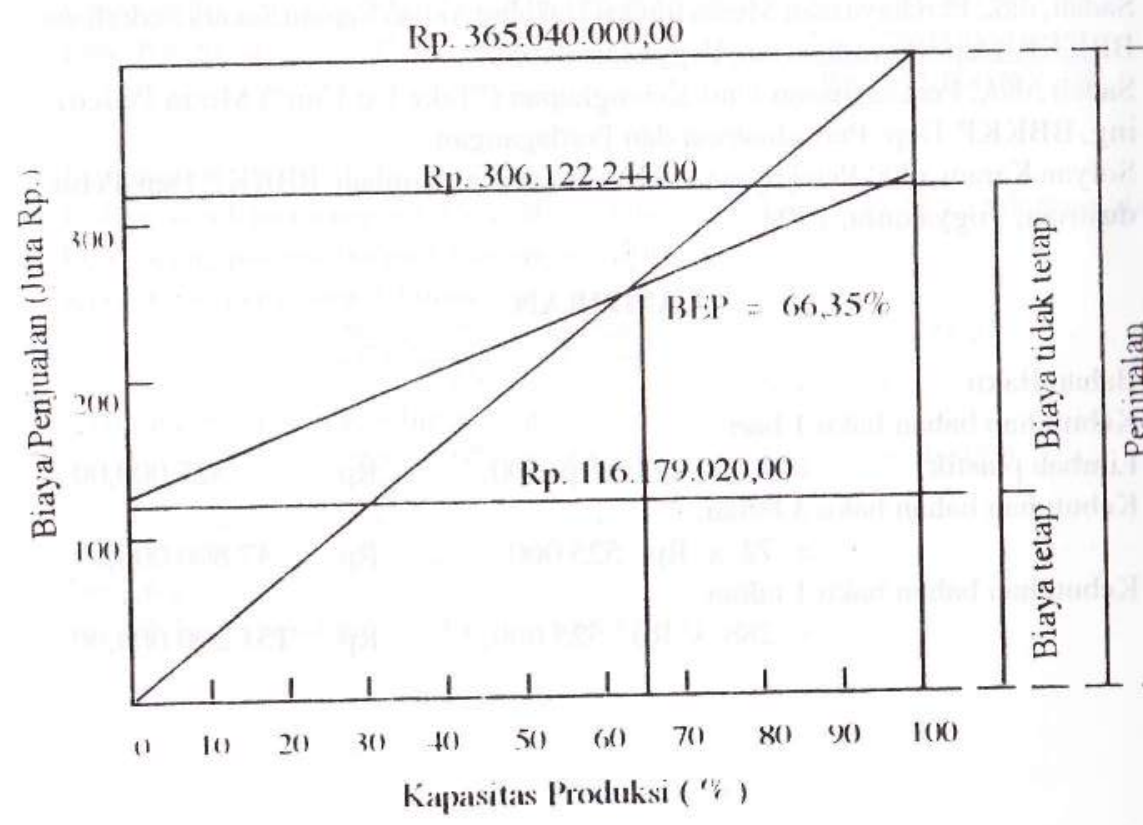




\section{KESIMPULAN}

Berdasarkan hasil perhitungan dengan menggunakan analisa ekonomi dapat disimpulkan sebagai berikut

1. Untuk kapasitas produksi $975 \mathrm{~kg}$ per hari atau $280.800 \mathrm{~kg}$ per tahun, modal yang dibutuhkan sebesar Rp. 272.543.306,00, yang terdiri dari modal tetap Rp.220 $228.000,00$ dan modal kerja Rp. 52.316.306,00.

2. Tenaga kerja yang dibutuhkan 11 orang.

.

produksi Rp. $1.090,18$ per kg.

4. Dan bila produk dijual dengan harga Rp. $1.300,00$ per kg, maka keunturgan sebesar $11,71 \%$. belum pajak sebesar $21,62 \%$ dan keuntungan sesudah 7 bulan dan sesudah pajak Waktu pengembalian modal sebelum pajak 3 tahun 7 bulan

5 tahun 6 bulan, maka diperoleh prosen rugi laba $66,35 \%$.

\section{DAFTAR PUSTAKA}

1. Perry's, "Chemical Engineer's Handbook", third edition.

"Plant Design and Economics for Chemi

2. Peters, M.S. and Timmertill Kagokusha, third edition, 1981

cal Engineer, Mc. Graw Hill Kagokusha, thic ecturan Secara Sederana

3. Sadali, dkk, Perekayasaan Mesin Injeksi Bakalan

BBKKP, Dep. Perindustrian, Yogyakarta 1986.

4. Sadali, dkk, Perekayasaan Unit Kelengkapan ('Take

ing, BBKKP, Dep. Periiadustrian dan Perdagangan.

5. Solyan Karani, dkk, Perckay

dustrian, Yogyakarta, 1994

\section{LAMPIRAN}

1. Bahan Baku

Kebutuhan bahan baku 1 hari.
Limbah plastik $=1.050 \mathrm{~kg} \times \mathrm{Rp} .500 .=\mathrm{Rp} . \quad 525.000,(00)$

Kebutuhan bahan baku 3 bulan.

$=72 \times \mathrm{Rp} .525 .000,-=$ Rp. $37.800 .000,00)$

Kebutuhan bahan baku I tahun

$=288 \times$ Rp. $525.000,=$ Rp. $151.200 .0(00,000$
2. Utilitas

Kebutuhan listrik tiap hari $=542 \mathrm{Kwh}$

Tarif I Kwh $=\mathrm{Rp}$. 179, dan biaya beban perbulan $\mathrm{Rp} .13 .770$,

Biaya listrik 3 bulan

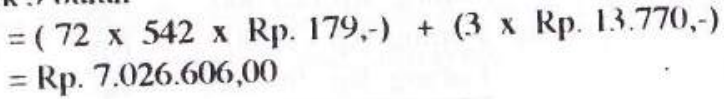

Biaya listrik 1 tahun

$=(288 \times 542 \times$ Rp. 179,- $)+\left(12 \times \mathrm{Rp}_{\mathrm{p}} \cdot 13.770,-\right)$

$=$ Rp. $28.106424,00$

Kebutuhan air tiap hari $=78 \mathrm{~m}^{3}$.

Tarip $1 \mathrm{~m}^{3}=$ Rp. 600 ,- dan harga heban tiap bulan Rp.6.000,- (sudah termasuk pemakaian air sebanyak $30 \mathrm{~m}^{3}$ ).

Biaya air 3 bulan

$=(72 \times 48 \times$ Rp. $600,-)+(3 \times$ Rp. $6 \cdot(000,-)$

$=\mathrm{Rp} \cdot 2 \cdot 097 \cdot 600,00$

Biaya air I tahun

$$
\begin{aligned}
& =(288 \times 48 \times \text { Rp. } 600,-)+(12 \times \text { Rp. } 6.000,-) \\
& =\text { Rp. } 8.390 .400,00
\end{aligned}
$$

3. Tanah dan hangunan.

Luas tanah $\quad=500 \mathrm{~m} 2 \times \mathrm{Rp} \cdot 125.000,-/ \mathrm{m} 2=\mathrm{Rp} \cdot 62.500 .000,00$

Luas bangunan $=360 \mathrm{~m} 2 \times$ Rp. $250.000,-/ \mathrm{m} 2=$ Rp. $90.000 .000,00$

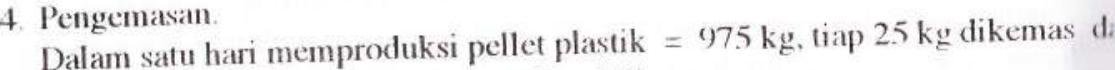
Dalam satu hari memproduksi pelfet plastik

Kebutuhan pengemas 3 bulan

$$
=\frac{72 \times 975 \times \text { Rp. } 200,}{25}
$$

$561.600,00$

Kebutuhan pengemas selama 1 tahun

$$
=\frac{288 \times 975 \times \text { Rp. } 200,}{25}
$$

$2.246 .400,00$

5. Peralatan

Jumlah harga peralatan $=\mathrm{Rp} .56 .440 .000,(00$ 
6. Jumlah gaji karyawan

\begin{tabular}{|c|c|c|c|c|}
\hline a. Manager/pemilik & 1 orang & Rp. $400.000,=$ & Rp. & $400.000,00$ \\
\hline h. Tenaga kerja kasar & 3 orang & Rp. $90.000,-=$ & $\mathrm{Rp}$. & $270.000,00$ \\
\hline c. Teknisi dan operator & 6 orang & Rp. $120.000,-=$ & Rp. & $720.000,00$ \\
\hline d. Administrasi dan gudang & I orang & Rp. $130.000,-=$ & Rp. & $130.000,00$ \\
\hline e. Pengemas & 1 orang & Rp. $90.000,-=$ & Rp. & $90.000,00$ \\
\hline & & 100000 & & $10.000,0$ \\
\hline gaji 3 bulan & Rp. & $4.830 .000,00$ & & \\
\hline lah gaji 1 tahun & Rp. & $19.320 .000,00$ & & \\
\hline
\end{tabular}

